JURNAL ILMU KESEHATAN BHAKTI HUSADA:

HEALTH SCIENCES JOURNAL

VOL. 12 NO. 02, DESEMBER 2021

DOI: $10.34305 / \mathrm{JIKBH} . \mathrm{V} 12 \mathrm{I} 2.324$
Ciptaan disebarluaskan di bawah

Lisensi Creative Commons Atribusi-

NonKomersial-BerbagiSerupa 4.0

\title{
POLA INFEKSI JAMUR KUKU (ONIKOMIKOSIS) JARI TANGAN DAN KAKI PADA PEKERJA TEMPAT PENITIPAN HEWAN PADA MEDIA POTATO DEXTROSE AGAR (PDA)
}

\author{
Norma Farizah Fahmi, Dwi Aprilia Anggraini, Yogi Khoirul Abror \\ STIKes Ngudia Husada Madura \\ rezaiei.cha@gmail.com
}

\begin{abstract}
Abstrak
Onikomikosis merupakan infeksi pada lempeng kuku yang dapat disebabkan oleh jamur dermatofita (Tinea unguium), non dermatofita atau yeast. Onikomikosis adalah kelainan kuku yang disebabkan oleh jamur dermatofita dan non-dermatofita. Infeksi onikomikosis menyebabkan kerusakan pada kuku yang menyebabkan lempeng kuku menebal, rapuh dan mudah hancur. Penelitian ini bertujuan untuk mengetahui identifikasi jamur kuku tangan dan kaki pada pekerja penitipan hewan. Jenis penelitian yang digunakan adalah penelitian deskriptif. Pengambilan sampel penelitian dilakukan di empat tempat penitipan hewan yang berbeda sebanyak 20 sampel di Surabaya dan tempat pemeriksaan dilakukan di Laboratorium Analis Kesehatan STIKes Ngudia Husada Madura. Metode pemeriksaan yang dilakukan melalui metode pengamatan langsung dan metode kultur jamur. Hasil identifikasi menunjukkan bahwa dari 20 sampel sebanyak 11 sampel (55\%) positif Tinea unguium (jamur kuku). Pada pengamatan metode kultur jamur hasil positif sebanyak 6 sampel (30\%) dengan kode P1, P4, P8, P11, P15 dan P20 terinfeksi oleh jamur Aspergillus sp, Penicillium 10\% dengan kode P5 dan P14, Rhizopus sp 5\% kode P18, Microsporum gypseum sebanyak 5\% kode P13, dan Trichophyton mentagrophytes 5\% kode P19. Hasil screening pada penelitian ini menunjukkan para pekerja belum memiliki hygiene diri yang baik khususnya dalam memelihara kebersihan kuku kaki dan tangan sehingga menyebabkan faktor resiko terjadinya infeksi jamur kuku.
\end{abstract}

Kata kunci $\quad$ : Jamur kuku (Onikomikosis), Dermatophyte, Potato dextrose agar

\section{Pendahuluan}

Menurut data Depkes RI prevalensi penyakit kulit diseluruh Indonesia di tahun
2012 adalah $8.46 \%$ kemudian meningkat di tahun 2013 sebesar 9\%. Penyakit kulit merupakan salah satu penyakit yang masih 
JURNAL ILMU KESEHATAN BHAKTI HUSADA:

HEALTH SCIENCES JOURNAL

VOL. 12 NO. 02, DESEMBER 2021

DOI: $10.34305 / \mathrm{JIKBH} . \mathrm{V} 12 \mathrm{I} 2.324$

menjadi masalah kesehatan masyarakat Indonesia. Penyakit jamur masih memiliki prevalensi yang tinggi (Dwi Candra Arianti, 2015). Jamur merupakan salah satu mikroorganisme penyebab penyakit pada manusia. Jamur merupakan makhluk hidup kosmopolitan yang tumbuh di mana saja baik di udara, tanah, air, pakaian, bahkan di tubuh manusia sendiri. Jamur dapat menyebabkan penyakit yang cukup parah bagi manusia (Hasanah, 2017).

Infeksi jamur kuku yang disebabkan oleh jamur dermatofita tersebut diistilahkan dengan Tinea unguium. Infeksi jamur tersebut menyebabkan terjadinya perubahan warna pada kuku menjadi putih, kuning atau kecoklatan, kuku mengalami onycholysis, pecah-pecah dan tidak rata infeksi onikomikosis menurut ahli tidak menyebabkan mortalitas, namun menimbulkan gangguan klinis yang signifikan, mengurangi estetika, bersifat kronis dan sulit diobati. Hal tersebut selanjutnya akan mengganggu kenyamanan dan menurunkan kualitas hidup penderita (Setianingsih et al., 2016).

Penyakit jamur onikomikosis pada kuku yang disebabkan oleh jamur dermatofita salah satu bentuk nya yaitu Onikomikosis Superfisialis Putih (OSPT) Kelainan ini jarang ditemui, terjadi bila
Ciptaan disebarluaskan di bawah Lisensi Creative Commons AtribusiNonKomersial-BerbagiSerupa 4.0

Internasional jamur menginvasi langsung lapisan superfisialis lempeng kuku. Bentuk klinis ditandai dengan bercak-bercak putih keruh berbatas tegas, menyebabkan kuku menjadi lunak, keras, dan mudah rapuh (Anugrah, 2016). Onikomikosis menyebabkan infeksi kronis pada kuku jari kaki atau kuku jari tangan. Biasanya onikomikosis disertai dengan infeksi jamur yang lama pada kaki. Kuku menjadi tebal,rapuh, dan tidak mengkilap. Lempeng kuku menjadi rusak dan berubah warna menjadi kehitaman, kekuningan atau suram. Penyakit ini paling sukar dan lama disembuhkan karena kuku terinfeksi menjadi rusak dan rapuh dan bentuknya tidak normal. Di bagian bawah kuku akan menumpuk sisa jaringan kuku yang rapuh sehingga tampak seperti kotoran (Kurniati, 2008).

Berdasarkan manifestasinya dibagi menjadi Distal Lateral Subungual Onikomikosis (DLSO), Superficial White Onikomikosis (SHOW), Proximal Subungual Onikomikosis (PSO) dan Endothrix Onikomikosis, Total Dystrophic Onikomikosis (TDO), mixed Pattern Onikomikosis dan Candida Onikomikosis. Masing-masing jenis onikomikosis memiliki manifestasi klinis khas dan dapat disebabkan oleh jenis jamur yang berbeda. Infeksi lebih sering terjadi pada jari kuku kaki 
JURNAL ILMU KESEHATAN BHAKTI HUSADA:

HEALTH SCIENCES JOURNAL

VOL. 12 NO. 02, DESEMBER 2021

DOI: $10.34305 / \mathrm{JIKBH} . \mathrm{V} 12 \mathrm{I} 2.324$

dibandingkan kuku jari tangan (Dwi Candra Arianti, 2015).

Penelitian dermatofitosis pada tahun 2011 didapatkan kasus sebanyak 3,0\%, tahun 2012 didapatkan kasus dermatofitosis sebanyak 2,9\% sedangkan pada tahun 2013 didapatkan kasus dermatofitosis sebanyak 3,0\%. Sebagian besar kasus onikomikosis (80- 90\%) disebabkan oleh jamur dermatofita khususnya Trichophyton rubrum dan T. Mentagrophytes (Afshar et al., 2014). Sementara itu sebanyak 5- 17\% kasus lainnya menurut Agrawal et al., (2015) dan Dubljanin et al., (2014) disebabkan oleh yeast Candida $s p$. serta non-dermatofita.

Jellinek et al., (2015) melaporkan kelompok non-dermatofita yang telah dilaporkan sebagai agen penyebab onikomikosis diantaranya Acremonium spp., Fusarium spp., Scopulariopsis spp., Scytalidium spp. dan Aspergillus spp.

Predisposisi onikomikosis adalah bertambahnya usia, kesehatan yang buruk, trauma sebelumnya, iklim yang hangat, lanjut usia, penderita diabetes dan orang dengan sirkulasi darah yang buruk pada kaki (Irianto, 2013).

Gejala yang sering kali tampak pada infeksi ini adalah kerusakan pada kuku, diantaranya kuku menjadi lebih tebal dan nampak terangkat dari dasar perlekatannya
Ciptaan disebarluaskan di bawah Lisensi Creative Commons AtribusiNonKomersial-BerbagiSerupa 4.0 Internasional.

atau onycholysis, pecah-pecah, tidak rata dan tidak mengkilap lagi, serta perubahan warna lempeng kuku menjadi putih, kuning, coklat, hingga hitam. Infeksi jamur dapat meningkatkan infeksi bakteri, selulitis, urtikaria kronis, dan sebagai reservoir jamur yang kemudian menginfeksi bagian tubuh lainnya serta dapat ditransmisikan atau ditularkan ke individu lainnya. Kuku merupakan bagian yang sering terkena infeksi. Kuku yang terinfeksi oleh jamur biasanya mengalami kelainan, seperti perubahan kerapuhan. Kelainan ini ditemukan pada kuku perajin batu bata yang setiap kali kontak langsung dengan tanah liat dan air (Lestari, 2017).

Tempat penitipan hewan ini adalah sebagai tempat penitipan sementara hewan peliharaan yang ditinggalkan pemilik karena keperluan mendesak dan membutuhkan waktu lebih dari satu hari. Biasanya hewan peliharaan dititipkan karena di rumah pemilik tidak ada yang bisa merawat anjing atau kucing. Pada area ini hewan peliharaan di rawat oleh kennel girl/ kennel boy (pegawai yang khusus menangani berbagai kebutuhan hewan peliharaan dan menjaga kebersihan kandang). Selain itu terdapat grooming area berfungsi sebagai tempat untuk memberikan pelayanan berupa jasa perawatan kuku, bulu, pembasmian kutu, 
JURNAL ILMU KESEHATAN BHAKTI HUSADA:

HEALTH SCIENCES JOURNAL

VOL. 12 NO. 02, DESEMBER 2021

DOI: $\underline{10.34305 / J I K B H . V 12 I 2.324}$

dan jamur pada hewan peliharaan. Grooming area juga memberikan jasa pelayanan pemijatan sederhana pada hewan peliharaan. Pemijatan ini memberikan efek untuk kelancaran peredaran darah pada hewan peliharaan. Pada tempat penitipan hewan juga terdapat fasilitas klinik dilengkapi dengan dokter hewan dan paramedik (Puspita, 2013).

Masalah kebersihan seringkali muncul pada setiap fasilitas khusus hewan. Perilaku hewan tidak mudah diatur untuk menjaga kebersihan. Oleh karena itu, tempat pelayanan kesehatan hewan harus terbebas dari berbagai hal yang berpotensi dapat memunculkan ancaman penyakit atau memperburuk kondisi kesehatan hewan. Di samping itu, pelayanan kesehatan hewan perlu berlangsung dalam suasana yang menyegarkan atau suasana yang nyaman dan dapat menenangkan. Suasana seperti itu dibutuhkan mengingat para pemilik hewan peliharaan datang ke sebuah klinik hewan, cenderung dalam kondisi perasaan sedih, cemas dan juga tegang karena memikirkan kondisi kesehatan hewan peliharaannya. Untuk itu maka suasana ruang atau tempat bagi mereka memerlukan dukungan elemenelemen yang bersifat segar atau fresh seperti warna yang lembut, sejuk, serta suasana ruangan yang bersih (Akmalia et al., 2017).

\section{Ciptaan disebarluaskan di bawah Lisensi Creative Commons Atribusi- NonKomersial-BerbagiSerupa 4.0 \\ Internasional.}

Dari pengamatan penulis ada hal yang perlu menjadi perhatian dalam petugas tempat penitipan hewan yaitu alat pelindung diri atau APD baik berupa sarung tangan, topi, sepatu masih belum dimiliki. Pada hal ini sangat penting dalam melindungi diri dari bahan infeksius dan bahan lain yang dapat mencelakakan. Hal tersebut dikarenakan tugas dari petugas kebersihan kandang/ kennel girl/ kennel boy yaitu mengawasi keadaan hewan (memotong kuku, menyisir rambut, memotong kuku, membersihkan mata, telinga, serta memandikan) melaporkan gangguan kesehatan maupun perilaku hewan kepada supervisor, melakukan perawatan dasar pada hewan (memandikan dan merawat kebersihan hewan). Petugas perawatan kandang bertanggung jawab untuk menjaga kebersihan sanitasi daerah tinggal hewan penampungan secara keseluruhan, memastikan ada air segar harus tersedia dan mudah diakses oleh setiap hewan setiap saat, melakukan pengamatan yang cermat terhadap binatang di kandang dan taman sepanjang hari, untuk melihat bahwa hewan aman, sehat, dan nyaman, memastikan setiap hewan harus memiliki akses ke tempat tidur bersih dan kering, mengoperasikan/ mengontrol alat cuci kain dan wadah makan (Universitas Brawijaya, 2012). 
JURNAL ILMU KESEHATAN BHAKTI HUSADA:

HEALTH SCIENCES JOURNAL

VOL. 12 NO. 02, DESEMBER 2021

DOI: $10.34305 / \mathrm{JIKBH} . \mathrm{V} 12 \mathrm{I} 2.324$
Ciptaan disebarluaskan di bawah

Lisensi Creative Commons Atribusi-

NonKomersial-BerbagiSerupa 4.0

Internasional.
Setianingsih et al., (2016) menyatakan, masyarakat yang bekerja sebagai peternak memiliki risiko terinfeksi Tinea unguium yang cukup tinggi. Kondisi ini menurut Agrawal et al., (2015) disebabkan karena peternak memiliki kemungkinan kontak langsung dengan hewan ternak yang tinggi serta dipengaruhi oleh kemungkinan sanitasi yang kurang higienis dan faktor predisposisi lainnya. Hal tersebut dibuktikan oleh Setianingsih et al., (2016) yang meneliti kejadian jamur kuku di Desa Konut dan Desa Sungai Lunuk Kalimantan diketahui bahwa sebanyak 35\% dari 40 peternak terinfeksi Tinea unguium. Berdasarkan latar belakang tersebut pada penelitian ini melakukan penelitian pada tempat penitipan hewan dikarenakan pekerja masih tetap aktif setiap hari melakukan tugas kebersihan kandang dan perawatan hewan serta jarang diadakannya penyuluhan terkait dengan tingkat higienitas dari zoonosis yang terjadi.

\section{Potato Dextrose Agar (PDA)} merupakan media yang sangat umum digunakan untuk mengembangbiakan dan menumbuhkan jamur/ khamir yang mengandung karbohidrat dalam jumlah cukup, terdiri dari 20\% kentang dan 2\% glukosa sehingga bakteri tidak dapat tumbuh. Akan tetapi, beberapa bakteri dapat memfermentasi karbohidrat menjadi sumber energi sehingga dengan penambahan kloramfenikol pada media PDA maka pertumbuhan bakteri akan terhambat. Media kentang yang terkandung dalam PDA mengandung fosfor, magnesium, zat besi, karbohidrat, protein, pati, dan kandungan gizi lainnya yang dibutuhkan. Selain itu, dekstrosa yang digunakan dalam media ini pun mengandung karbohidrat yang baik untuk pertumbuhan jamur (Iswanto, 2015).

Penelitian ini termasuk jenis penelitian dengan metode analisis deskriptif menggunakan pendekatan laboratorik. Penggambaran dari penelitian ini yaitu dengan melihat kontaminasi telur nematoda usus yang meliputi ada tidaknya telur nematoda usus serta apakah ada perbedaan jenis telur nematoda usus pada kuku jari tangan menggunakan 1 larutan $\mathrm{NaCl}$ jenuh.

Penelitian menggunakan metode deskriptif. Sampel penelitian adalah kuku jari tangan pekerja tempat penitipan hewan yang berjumlah 20 responden. Pengambilan sampel dilakukan di empat tempat penitipan hewan di Surabaya yang dilengkapi dengan fasilitas grooming area. Pengujian sampel dilakukan di Laboratorium D3 Analis Kesehatan STIKes Ngudia Husada Madura. Pemeriksaan onikomikosis dilakukan melalui 2 teknik yaitu pemeriksaan langsung 
JURNAL ILMU KESEHATAN BHAKTI HUSADA:

HEALTH SCIENCES JOURNAL

VOL. 12 NO. 02, DESEMBER 2021

DOI: $10.34305 / \mathrm{JIKBH} . \mathrm{V} 12 \mathrm{I} 2.324$
Ciptaan disebarluaskan di bawah

Lisensi Creative Commons Atribusi-

NonKomersial-BerbagiSerupa 4.0

Internasional. dan kultur jamur. Pada pemeriksaan mikroskopis, kuku kaki responden didesinfeksi dengan alkohol 70\%. Diambil kerokan kuku dengan menggunakan scalpel steril. Hasil kerokan kuku kaki diletakan di objek glass dan ditambahkan $\mathrm{KOH} 10-20 \%$ sebanyak 1 tetes kemudian ditutup dengan cover glass dan didiamkan selama 10 menit. Pemeriksaan secara langsung di bawah mikroskop perbesaran lensa objektif 10X dan 40X. Hasil positif bila ditemukan spora atau hifa dermatofita atau non-dermatofita sedangkan hasil negatif bila tidak ditemukan spora atau jamur dermatofita atau nondermatofita. Pemeriksaan kultur jamur dilakukan dengan cara penanaman sampel pada media Potato Dextrose Agar (SDA). Sampel kerokan kuku ditanam secara tersebar pada media PDA dan diinkubasi pada pada suhu ruang $\pm 280 \mathrm{C}$ selama $3-5$ hari.

\section{Hasil dan Pembahasan}

Tabel 1. Hasil metode pengamatan langsung identifikasi Tinea unguium (jamur kuku) pada pekerja tempat penitipan hewan

\begin{tabular}{|c|c|c|c|c|c|}
\hline Nomor & $\begin{array}{l}\text { Kode Sampel } \\
\text { dan tempat } \\
\text { pengambilan } \\
\text { sampel }\end{array}$ & $\begin{array}{l}\text { Umur } \\
\text { (Tahun) }\end{array}$ & Jenis kelamin & $\begin{array}{l}\text { Karakteristik } \\
\text { gejala } \\
\text { kerusakan kuku } \\
\text { yang dialami }\end{array}$ & $\begin{array}{l}\text { Hasil morfologi } \\
\text { jamur }\end{array}$ \\
\hline 1 & $\mathrm{P} 1$ & 28 & Laki-laki & $\begin{array}{l}\text { Kuku berwarna } \\
\text { kecoklatan }\end{array}$ & $\begin{array}{l}\text { Positif } \\
\text { Aspergillus sp }\end{array}$ \\
\hline 2 & $\mathrm{P} 2$ & 30 & Laki-laki & $\begin{array}{l}\text { Kuku berwarna } \\
\text { putih sehat }\end{array}$ & Negatif \\
\hline 3 & P3 & 33 & Laki-laki & $\begin{array}{l}\text { Kuku berwarna } \\
\text { putih sehat }\end{array}$ & Negatif \\
\hline 4 & $\mathrm{P} 4$ & 29 & Laki-laki & $\begin{array}{l}\text { Kuku berwarna } \\
\text { kuning pucat dan } \\
\text { terdapat kotoran }\end{array}$ & $\begin{array}{l}\text { Positif } \\
\text { Aspergillus } s p\end{array}$ \\
\hline 5 & P5 & 20 & Laki-laki & $\begin{array}{l}\text { Kuku berwarna } \\
\text { kuning pucat dan } \\
\text { mengalami } \\
\text { gejala kerusakan }\end{array}$ & Positif Penicillium \\
\hline 6 & P6 & 36 & Perempuan & $\begin{array}{l}\text { Kuku berwarna } \\
\text { putih sehat }\end{array}$ & Negatif \\
\hline 7 & P7 & 40 & Perempuan & $\begin{array}{l}\text { Kuku berwarna } \\
\text { putih sehat }\end{array}$ & Negatif \\
\hline 8 & P8 & 28 & Perempuan & $\begin{array}{l}\text { Kuku berwarna } \\
\text { kecoklatan }\end{array}$ & $\begin{array}{l}\text { Positif } \\
\text { Aspergillus sp }\end{array}$ \\
\hline 9 & P9 & 25 & Laki-laki & $\begin{array}{l}\text { Kuku berwarna } \\
\text { putih sehat }\end{array}$ & Negatif \\
\hline 10 & $\mathrm{P} 10$ & 24 & Laki-laki & $\begin{array}{l}\text { Kuku berwarna } \\
\text { putih sehat }\end{array}$ & Negatif \\
\hline
\end{tabular}


JURNAL ILMU KESEHATAN BHAKTI HUSADA:

HEALTH SCIENCES JOURNAL

VOL. 12 NO. 02, DESEMBER 2021

DOI: $10.34305 / \mathrm{JIKBH} . \mathrm{V} 12 \mathrm{I} 2.324$
Ciptaan disebarluaskan di bawah Lisensi Creative Commons AtribusiNonKomersial-BerbagiSerupa 4.0 Internasional.

\begin{tabular}{|c|c|c|c|c|c|}
\hline 11 & P11 & 35 & Laki-laki & $\begin{array}{l}\text { Kuku berwarna } \\
\text { kuning pucat } \\
\text { agak kecoklatan }\end{array}$ & $\begin{array}{l}\text { Positif } \\
\text { Aspergillus sp }\end{array}$ \\
\hline 12 & P12 & 21 & Perempuan & $\begin{array}{l}\text { Kuku berwarna } \\
\text { putih bersih }\end{array}$ & Negatif \\
\hline 13 & P13 & 25 & Laki-laki & $\begin{array}{lr}\text { Kuku } & \text { berwarna } \\
\text { kuning } & \text { pucat } \\
\text { dengan } & \text { gejala } \\
\text { rusak } & \end{array}$ & $\begin{array}{l}\text { Positif } \\
\text { Microsporum } \\
\text { gypseum }\end{array}$ \\
\hline 14 & P14 & 27 & Perempuan & $\begin{array}{l}\text { Kuku berwarna } \\
\text { kuning }\end{array}$ & Positif Penicillium \\
\hline 15 & P15 & 45 & Laki-laki & $\begin{array}{l}\text { Kuku berwarna } \\
\text { kuning } \\
\text { kecoklatan }\end{array}$ & $\begin{array}{l}\text { Positif } \\
\text { Aspergillus sp }\end{array}$ \\
\hline 16 & P16 & 23 & Laki-laki & $\begin{array}{l}\text { Kuku berwarna } \\
\text { putih bersih }\end{array}$ & Negatif \\
\hline 17 & P17 & 31 & Laki-laki & $\begin{array}{l}\text { Kuku berwarna } \\
\text { putih bersih }\end{array}$ & Negatif \\
\hline 18 & P18 & 39 & Perempuan & $\begin{array}{l}\text { Kuku berwarna } \\
\text { kuning pucat dan } \\
\text { ada beberapa } \\
\text { kerusakan }\end{array}$ & Positif Rhizopus \\
\hline 19 & P19 & 20 & Perempuan & $\begin{array}{lr}\text { Kuku } & \text { berwarna } \\
\text { kuning } & \text { dan } \\
\text { terdapat } & \text { kotoran } \\
\text { hitam } & \end{array}$ & $\begin{array}{l}\text { Positif } \\
\text { Trichophyton } \\
\text { mentagrophytes }\end{array}$ \\
\hline 20 & $\mathrm{P} 20$ & 20 & Laki-laki & $\begin{array}{l}\text { Kuku berwarna } \\
\text { kuning pucat }\end{array}$ & $\begin{array}{l}\text { Positif } \\
\text { Aspergillus sp }\end{array}$ \\
\hline
\end{tabular}

Tabel 2. Frekuensi dan persentase spesies jamur Tinea unguium (jamur kuku) pada pekerja tempat penitipan hewan

\begin{tabular}{llc}
\hline Hasil Morfologi Jamur & Jumlah & Prosentase \\
& & \\
\hline Positif Aspergillus sp & 6 & $30 \%$ \\
\hline Positif Penicillium & 2 & $10 \%$ \\
\hline Positif Microsporum gypseum & 1 & $5 \%$ \\
& & \\
\hline Positif Rhizopus sp & 1 & $5 \%$ \\
\hline Positif Trichophyton mentagrophytes & 1 & $5 \%$ \\
\hline Negatif & & \\
\hline
\end{tabular}


JURNAL ILMU KESEHATAN BHAKTI HUSADA:

HEALTH SCIENCES JOURNAL

VOL. 12 NO. 02, DESEMBER 2021

DOI: $10.34305 / \mathrm{JIKBH} . \mathrm{V} 12 \mathrm{I} 2.324$
Ciptaan disebarluaskan di bawah

Lisensi Creative Commons Atribusi-

NonKomersial-BerbagiSerupa 4.0

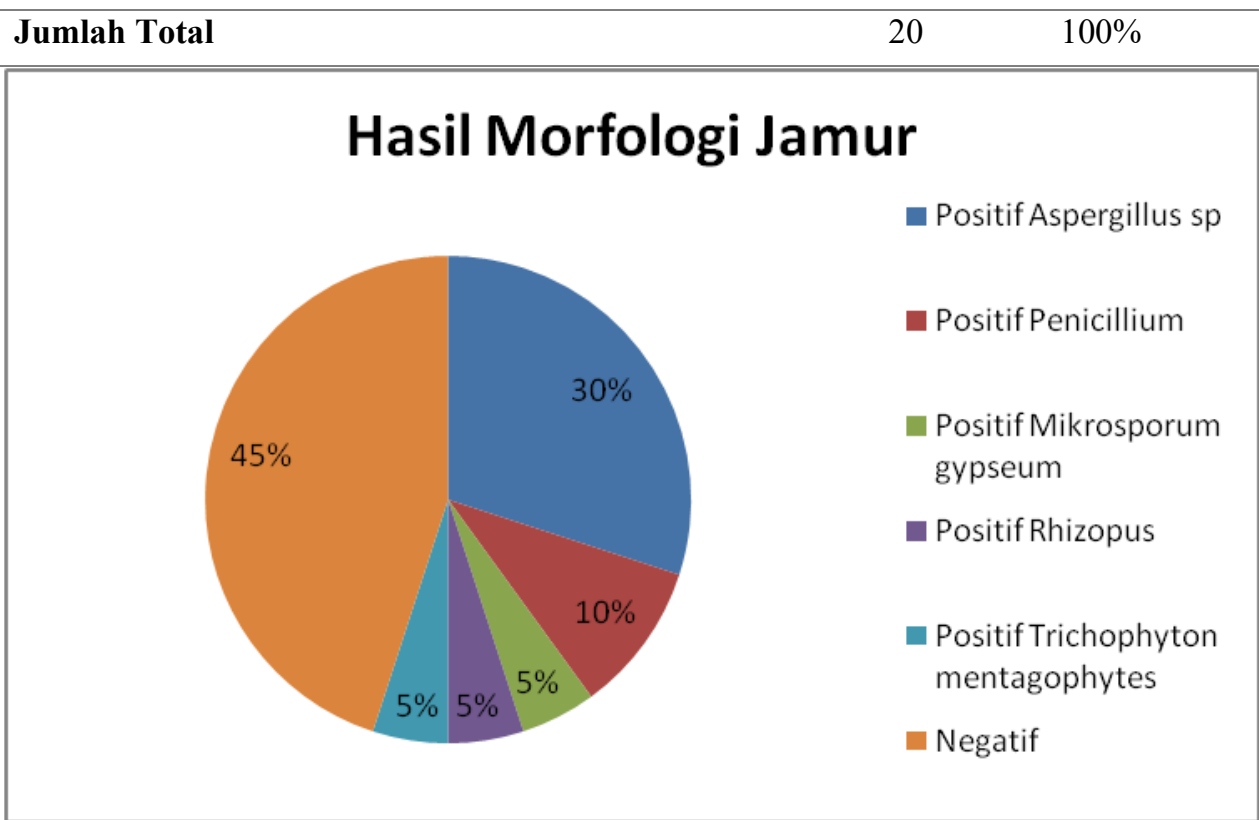

Gambar 1. Diagram frekuensi dan persentase spesies jamur Tinea unguium (jamur kuku) pada pekerja tempat penitipan hewan

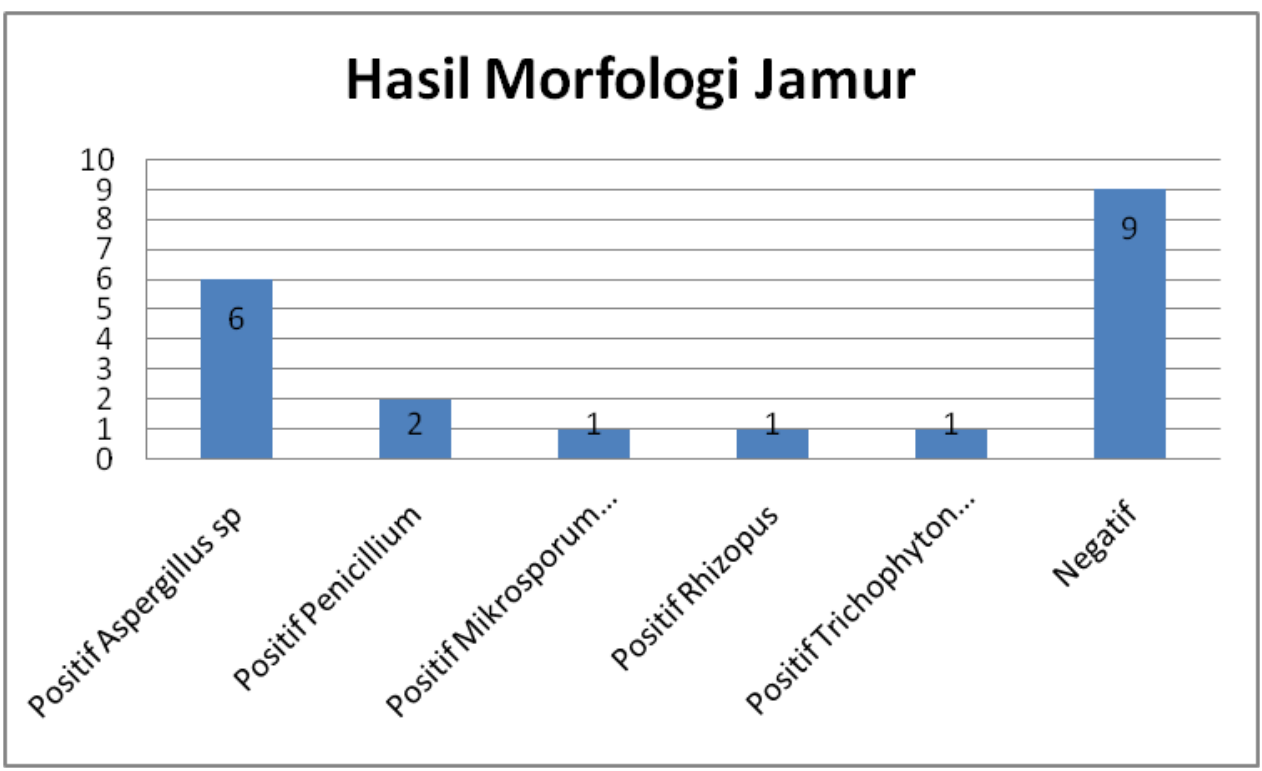

Gambar 2. Diagram frekuensi dan persentase spesies jamur Tinea unguium (jamur kuku) pada pekerja tempat penitipan hewan 
JURNAL ILMU KESEHATAN BHAKTI HUSADA:

HEALTH SCIENCES JOURNAL

VOL. 12 NO. 02, DESEMBER 2021

DOI: $10.34305 / \mathrm{JIKBH} . \mathrm{V} 12 \mathrm{I} 2.324$
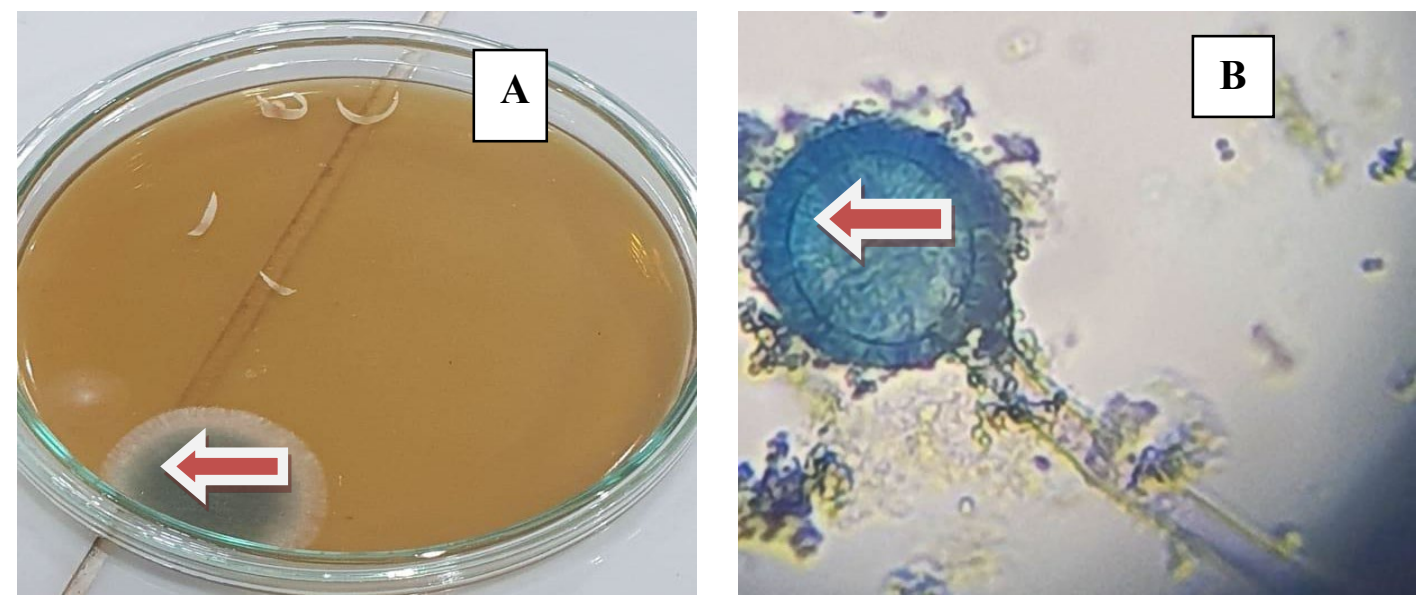

Keterangan:

A. Gambaran mikroskopis Aspergillus sp (tanda panah merah). Warna koloni bervariasi dari kuning kecoklatan sampai keabu abuan. Teksturnya seperti beludru bergranula. Terdapat zona pertumbuhan.

B. Gambaran Aspergillus dengan perbesaran 40x dan pewarnaan lactophenol cotton blue. Mempunyai hifa bersepta dengan konidiofor (batang) berdinding halus. Ciri khasnya berupa konidia halus yang menyebar di sepanjang sisi vesikula (bagian kepala) Aspergillus sp.
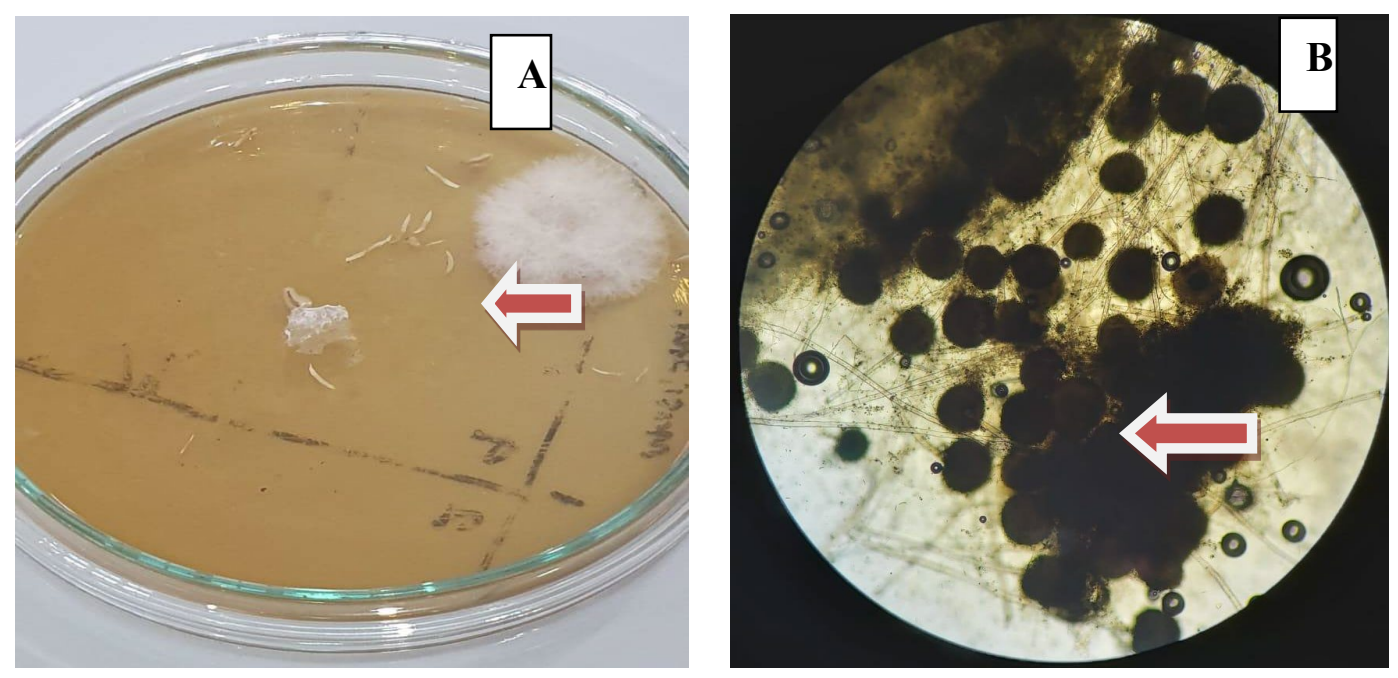

Keterangan: 
JURNAL ILMU KESEHATAN BHAKTI HUSADA:

HEALTH SCIENCES JOURNAL

VOL. 12 NO. 02, DESEMBER 2021

DOI: $10.34305 / \mathrm{JIKBH} . \mathrm{V} 12 \mathrm{I} 2.324$
Ciptaan disebarluaskan di bawah Lisensi Creative Commons AtribusiNonKomersial-BerbagiSerupa 4.0

Internasional.

A. Gambaran mikroskopis Rhizopus yang berbulu menyerupai wol atau kapas putih dan tumbuh memenuhi cawan petri. Tidak terdapat radial furrow (garis radial), konsentris furrow (garis tengah) dan zonasi pertumbuhan.

B. Gambaran mikroskopik Rhizopus dengan perbesaran 40x dan pewarnaan lactophenol cotton blue. Ciri khasnya berupa sporangium bulat, rhizoid pada pangkal batang sporangiofor, kolumela, dan hifa septat.
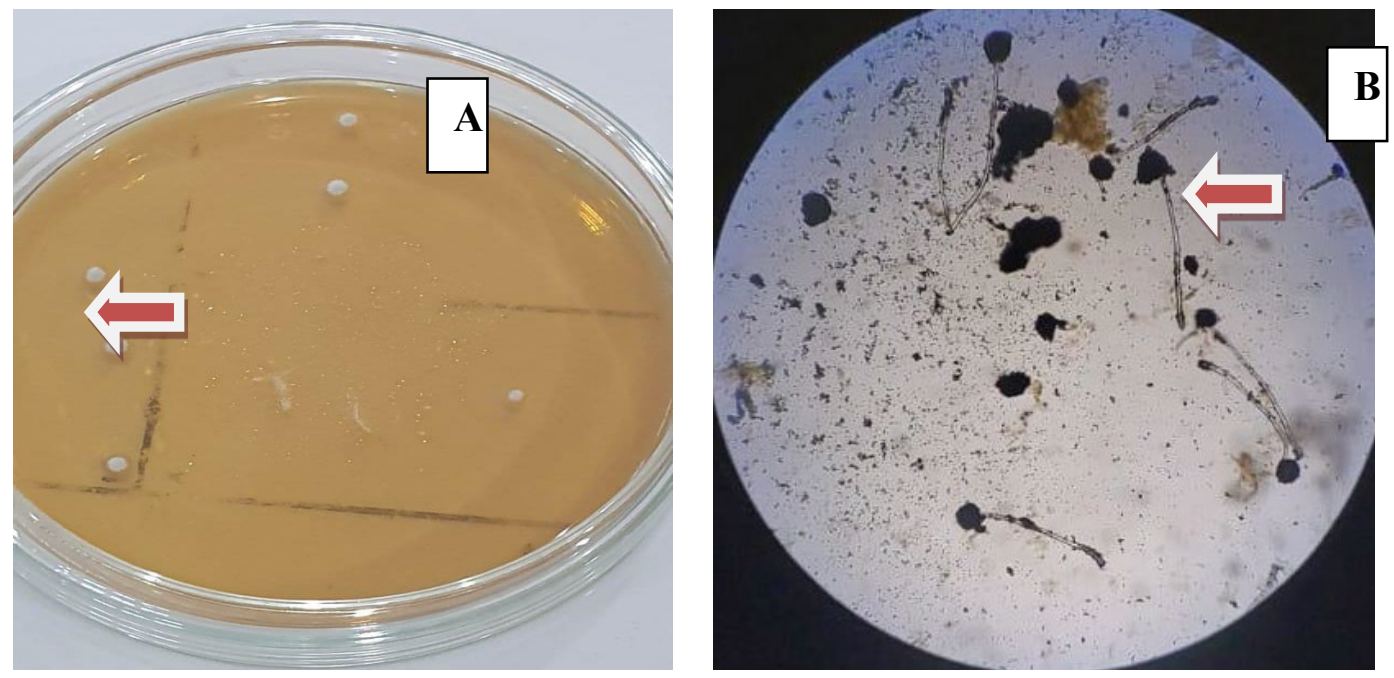

Keterangan:

A. Gambaran mikroskopis Penicillium yang bertekstur bergranula bertepung dengan variasi warna hijau dan hijau keabu-abuan permukaan cembung bertepi putih.

B. Tampilan mikroskopis Penicillium yang memiliki septat dengan hifa berhialin. Sebagian besar konidiofor bercabang. Pada gambar diatas konidiofor tersambung sampai hifa. 
JURNAL ILMU KESEHATAN BHAKTI HUSADA:

HEALTH SCIENCES JOURNAL

VOL. 12 NO. 02, DESEMBER 2021

DOI: $\underline{10.34305 / J I K B H . V 12 I 2.324}$
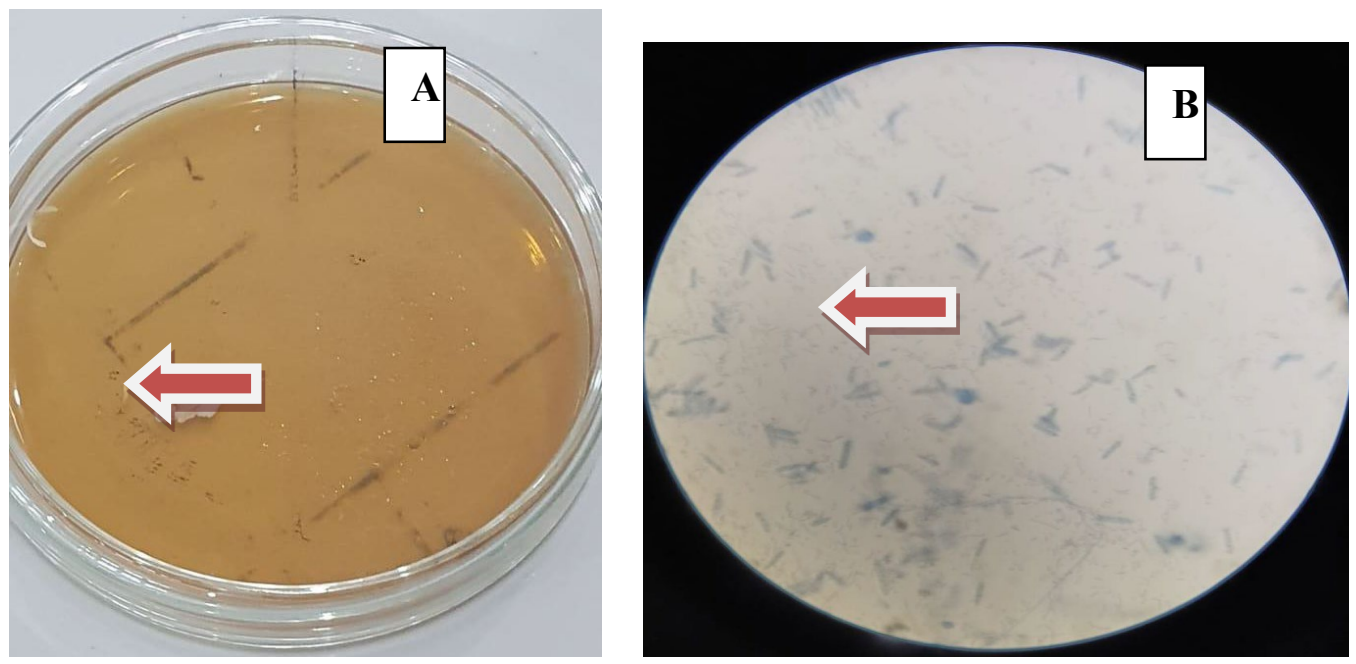

Keterangan:

A. Gambaran mikroskopis Trichophyton mentagrophytes yang bertekstur seperti tenunan lilin, berwarna putih sampai putih kekuningan yang agak terang atau berwarna violet merah. Kadang bahkan berwarna pucat kekuningan dan coklat. Koloninya seperti putih hingga krem dengan permukaan seperti tumpukan kapas pada PDA (tidak berpigmen).

B. Tampilan mikroskopis Trichophyton mentagrophytes yang memiliki hifa seperti tetesan lilin dan spiral, spora berbentuk bulatan kecil, miselium bersekat, makrokonidia berbentuk seperti cerutu, mikrokonidia bergerombol seperti anggur. 
JURNAL ILMU KESEHATAN BHAKTI HUSADA:

HEALTH SCIENCES JOURNAL

VOL. 12 NO. 02, DESEMBER 2021

DOI: $10.34305 / \mathrm{JIKBH} . \mathrm{V} 12 \mathrm{I} 2.324$
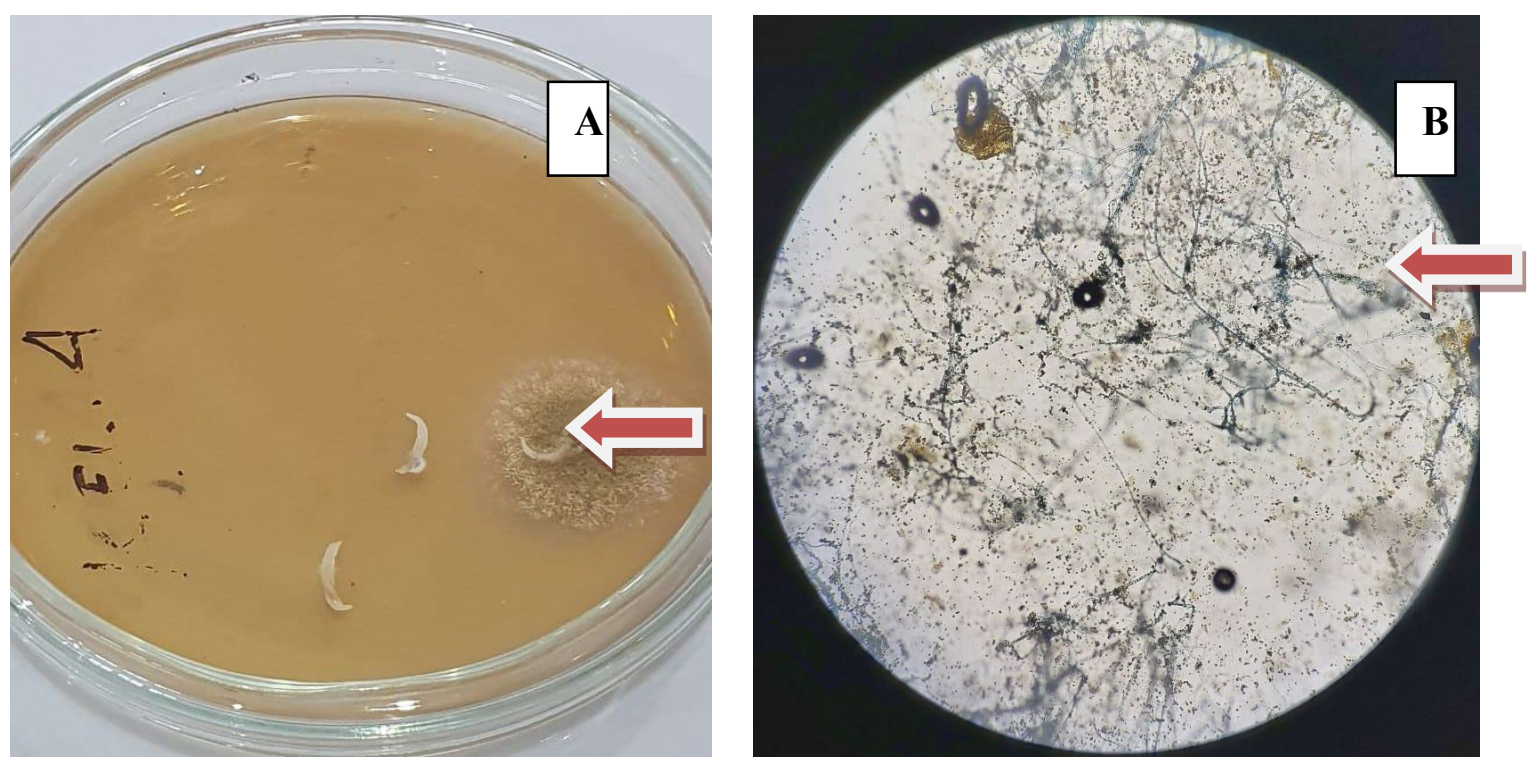

Keterangan:

A. Gambaran mikroskopis Microsporum gypseum tumbuh dengan cepat, menyebar dengan permukaan yang mendatar dan sedikit berserbuk merah coklat hingga kehitam-hitaman terkadang dengan warna ungu. Serbuk yang berada di permukaan koloni mengandung makrokonidia.

B. Tampilan mikroskopis Microsporum gypseum macroconidia yang dihasilkan dalam jumlah yang besar. Dindingnya tipis dengan ketebalan 8-16 x $20 \mu \mathrm{m}$, kasar dan memiliki 4-6 septa, dan berbentuk oval. Makrokonidia terdiri dari 4-6 sel. Mikrokonidia juga dapat nampak, meskipun jarang dihasilkan, terkadang pula mudah tumbuh pada subkultur setelah beberapa kali berganti media pada laboratorium (pada gambar diatas kurang terlalu bagus untuk fotonya).

\section{Hasil dan Pembahasan}

Hasil identifikasi yang dilakukan terhadap 20 sampel kerokan kuku jari tangan dan kaki pada pekerja tempat penitipan hewan di Surabaya diketahui sebanyak 8 sampel peternak babi (55\%) positif onikomikosis (jamur kuku). Hal tersebut ditegakkan berdasarkan pemeriksaan metode kultur jamur didapatkan 11 sampel positif terdapat pertumbuhan jamur pada media PDA dan dapat diidentifikasi secara mikroskopis. Hasil identifikasi terhadap 11 sampel positif didapatkan bahwa onikomikosis pada pekerja tempat penitipan 
JURNAL ILMU KESEHATAN BHAKTI HUSADA:

HEALTH SCIENCES JOURNAL

VOL. 12 NO. 02, DESEMBER 2021

DOI: $\underline{10.34305 / J I K B H . V 12 I 2.324}$

hewan disebabkan oleh jamur Aspergillus sp sebanyak 30\% (Gambar 1), Penicillium 10\% (Gambar 1) sebanyak 10\%, Microsporum gypseum (Gambar 1) sebanyak 5\%, Trichophyton mentagrophytes $5 \%$ dan Rhizopus sp (Gambar 1) dengan presentasi sebanyak 5\%. Pengamatan terhadap koloni jamur pada sampel positif dilanjutkan melalui pengamatan secara mikroskopis untuk mengetahui struktur jamur sebagai dasar identifikasi. Berdasarkan hasil pengamatan mikroskopis, sebanyak 6 preparat dengan kode sampel (P1, P4, P8, P11, P15, dan P20) memiliki karakteristik yang sama dengan genus Aspergillus sp. Adapun karakteristik yang teramati diantaranya memiliki hifa bersekat dan bercabang, konidiofor, sterigma dan bentuk konidia yang khas dari genus Aspergillus. Hasil tersebut sesuai dengan Mizana et al., (2016) yang menyatakan bahwa Jamur Aspergillus $s p$ adalah jamur berbentuk benang yang sporanya selalu berada di udara. Salah satu faktor yang mempengaruhi pertumbuhan jamur adalah suhu, suhu ini akan mempengaruhi reaksi kimia dan reaksi enzimatis pada mikroba yang berpengaruh pada pertumbuhan mikroba. Selain itu, suhu juga akan mempengaruhi kecepatan pertumbuhan mikroba. Jamur Aspergillus sp dapat menghasilkan beberapa toksin salah

\section{Ciptaan disebarluaskan di bawah Lisensi Creative Commons Atribusi- NonKomersial-BerbagiSerupa 4.0 \\ Internasiona}

satunya adalah aflatoksin. Aflatoksin adalah jenis toksin yang bersifat karsinogenik dan hepatotoksik. Gangguan kesehatan yang diakibatkan spora kapang akan menyerang saluran pernapasan. Reaksi alergi karena terpapar oleh spora jamur atau sel vegetatif fungi adalah demam, asma kandidiasis, dan superficial mikosis.

Berdasarkan persamaan karakteristik tersebut maka spesies jamur penyebab Tinea unguium pada sampel kode (P1, P4, P8, P11, P15, dan P20) teridentifikasi sebagai Aspergillus sp. Pada preparat sampel kode P18 teridentifikasi sebagai Rhizopus sp. Hal ini sesuai dengan penelitian Bitew (2018) menyatakan saat ini dermatofitosis cukup banyak disebabkan oleh kelompok nondermatofita. Dari 164 jenis jamur penyebab dermatofitosis yang diteliti sebanyak 47,6 \% nya merupakan kelompok non-dermatofita sedangkan $52,4 \%$ nya termasuk ke dalam dermatofita. Infeksi Aspergillus sp. pada kuku sebagian besar terjadi melalui kontak secara langsung pada sumber kontaminan (Amirsyam, 2008). Bongomin et al., (2018) menyatakan Aspergillus sp. merupakan agen onikomikosis non-dermatofita yang menyebabkan infeksi kuku. Karakteristik diagnosa onikomikosis oleh Aspergillus sp. dapat diamati melalui pengamatan langsung positif, kultur jamur positif atau deteksi 
JURNAL ILMU KESEHATAN BHAKTI HUSADA:

HEALTH SCIENCES JOURNAL

VOL. 12 NO. 02, DESEMBER 2021

DOI: $10.34305 / \mathrm{JIKBH} . \mathrm{V} 12 \mathrm{I} 2.324$
Ciptaan disebarluaskan di bawah

Lisensi Creative Commons Atribusi-

NonKomersial-BerbagiSerupa 4.0

Internasional. molekuler. Onikomikosis non dermatofita selain dapat disebabkan oleh Aspergillus sp. juga dapat disebabkan oleh Rhizopus sp. (Martínez-Herrera et al., 2015). Penelitian yang dilakukan oleh Setianingsih et al., (2016) pada ternak babi di Kalimantan Tengah diketahui infeksi onikomikosis tidak disebabkan oleh jamur dermatofita tetapi oleh non-dermatofita. Adapun jamur nondermatofita yang menyebabkan infeksi selain disebabkan oleh Aspergillus sp., juga disebabkan oleh Rhizopus sp.

Penyakit sistemik yang menyertai penyakit yang disebabkan jamur patogen berupa jamur primer dan oportunistik apabila kasus Tinea unguium tidak mendapatkan pengobatan. Infeksi jamur yang terdiagnosis paling sering disebabkan oleh jamur patogen dari genus Candida, Cryptococcus dan Aspergillus. Penyakit yang sering ditimbulkan oleh jamur patogen di permukaan kulit berupa dermatofitosis athlete's foot (Tinea pedis), Tinea capitis dan infeksi kuku (Tinea unguium) (Brown et al., 2012). Pada sistem pernapasan, ukuran partikel jamur yang kecil dapat terhirup dan masuk mencapai alveolus paru-paru. Partikel jamur yang masuk bersama debu dan bersifat alergen juga dapat memicu timbulnya berbagai penyakit seperti asma dan aspergilosis bronkopulmoner (salah satu jenis mikosis pulmonal) (Iqbal et al., 2016). Berbagai komponen jamur dalam ruangan seperti spora jamur dan produk metabolismenya seperti mikotoksin, dinding sel, senyawa organik volatil dan antigen sel jamur dapat menimbulkan masalah kesehatan manusia terutama pada orang dengan penyakit pernafasan, bayi, orang tua, dan pasien yang sedang menjalani terapi imunosupresif (Ayanbimpe et al., 2010). Penyakit lain yang dapat timbul akibat infeksi jamur dapat berupa mikosis superfisial, mikosis kutan, mikosis subkutan sampai mikosis sistemik yang menginfeksi organ dalam seperti paru-paru, rektum, uretra dan organ lain secara luas yang dapat berakibat.

Pada hasil penelitian diatas Microsporum $s p$, Trichophyton $s p$ dan dari genus Aspergillus sp yang termasuk jamur oportunistik yaitu mikrofungi yang menempel pada inang. Mikrofungi yang oportunis banyak terdapat pada daerah tropik dan dapat menjadi patogen apabila kesehatan seseorang sedang menurun. Hasil dari kerokan pasien, didapatkan kesimpulan penyebab Tinea pedis karena faktor: Faktor suhu dan kelembaban di mana banyak keringat yang paling sering terserang penyakit jamur ini, faktor keadaan sosial serta kurangnya kebersihan, faktor umur dan 
JURNAL ILMU KESEHATAN BHAKTI HUSADA:

HEALTH SCIENCES JOURNAL

VOL. 12 NO. 02, DESEMBER 2021

DOI: $\underline{10.34305 / J I K B H . V 12 I 2.324}$

jenis kelamin, faktor kontak dengan individu lain (penularan) infeksi akibat kontak dengan orang yang terinfeksi atau permukaan yang terkontaminasi, misalnya pada pemakaian handuk dan pakaian. Faktor kondisi kesehatan dimana terdapat jamur oportunistik menyerang penderita penyakit infeksi, dengan daya tahan tubuh yang sudah tidak berfungsi normal lagi. Dalam kasus ini jamur oportunistik yang terdapat pada penderita disebabkan karena daya tahan tubuh yang menurun.

Berdasarkan hasil identifikasi hasil penelitian lainnya kasus onikomikosis menunjukkan bahwa sebagian besar fungi yang terisolasi dari golongan mikrofungi dermatofita yang bersifat patogen yaitu Microsporum gypseum, Trichophyton mentagrophytes, Trichophyton rubrum, Epidermophyton floccosum, sedangkan lainnya golongan kontaminan yaitu mikrofungi yang menempel pada inang seperti pada isolasi genus Aspergillus fumigatus, Aspergillus niger, Aspergillus flavus. Mikrofungi yang oportunis banyak terdapat pada daerah tropik dan dapat menjadi patogen apabila kesehatan seseorang sedang menurun misalnya pada Aspergillus fumigatus, spesies ini dapat tumbuh pula pada bronkus paru-paru dan

\section{Ciptaan disebarluaskan di bawah Lisensi Creative Commons Atribusi- NonKomersial-BerbagiSerupa 4.0 \\ Internasional}

tidak terganggu pertumbuhanya pada peningkatan suhu (bersifat termofilik).

Banyaknya Aspergillus spp. yang ditemukan pada ruangan rumah sakit dengan karakteristik terbuka dan memiliki sistem ventilasi yang baik, diduga Aspergillus spp. yang banyak terdapat di tanah sebagai saprofit, masuk ke dalam ruangan melalui kondisi meteorologi/cuaca kemarau yang menyediakan kelembaban dan suhu yang memungkinkan.

\section{Kesimpulan dan Saran}

Berdasarkan penelitian yang telah dilakukan dapat ditarik kesimpulan sebagai berikut: Sebanyak 55\% peternak babi di Banjar Paang Kaja dan Banjar Semaga Desa Penatih Kecamatan Denpasar Timur berdasarkan pemeriksaan laboratorium positif onikomikosis. Hasil identifikasi dengan metode kultur jamur diketahui jamur penyebab onikomikosis adalah dermatofita dan non dermatofita yaitu sebanyak 6 sampel (30\%) terinfeksi oleh jamur Aspergillus sp, Penicillium 10\%, Rhizopus sp 5\%, Microsporum gypseum sebanyak 5\%, dan Trichophyton mentagrophytes 5\%. Sebagai penyempurnaan identifikasi jamur dermatofita dan non dermatofita penyebab onikomikosis maka perlu dilakukan identifikasi lanjutan untuk mengetahui 
JURNAL ILMU KESEHATAN BHAKTI HUSADA:

HEALTH SCIENCES JOURNAL

VOL. 12 NO. 02, DESEMBER 2021

DOI: $10.34305 / \mathrm{JIKBH} . \mathrm{V} 12 \mathrm{I} 2.324$

secara pasti spesies penyebab onikomikosis.

Setelah selesai bekerja para pekerja sebaiknya membersihkan kuku dan langsung mengeringkannya. Bagi yang terinfeksi jamur terutama pada keadaan kuku yang sudah terangkat sampai setengah bagian kuku sebaiknya kuku dipotong habis sampai batas kuku yang terangkat dan setiap hari dibersihkan dengan alkohol swab atau kapas yang dibasahi dengan alkohol. Pada keadaan kuku yang bernanah disarankan untuk melakukan pemeriksaan lebih lanjut ke Dokter. Gunakan peralatan kuku pribadi misalnya: gunting kuku, kikir kuku, sikat kuku, pendorong kutikula. Jika menggunakan milik orang lain dapat menyebabkan penularan jamur kuku.

\section{Daftar Pustaka}

Afshar, P., Khodavaisy, S., Kalhori, S., Ghasemi, M., \& Razavyoon, T. (2014). Onychomycosis in North-East of Iran. Iranian Journal of Microbiology, 6(2), 98-103.

Agrawal, A., Shanker, U., Goyal, A., Singh, P. K., Bhooshan, S., \& Pandey, D. N. (2015). Clinical and Microbiological study of Tinea unguium in a Tertiary Care Centre. Int. J. Curr. Microbiol. App. Sci, 4(4), 899-905.

Akmalia, A. Y., Widyaevan, D. A., \& Anwar, H. (2017). Perancangan Klinik Anjing dan Kucing dengan Pendekatan Programatik. EProceedings of Art \&
Ciptaan disebarluaskan di bawah

Lisensi Creative Commons Atribusi-

NonKomersial-BerbagiSerupa 4.0

Internasional

Design, 4(3).

Amirsyam, N. M. (2008). Mikologi dan Mikrologi Kedokteran Beberapa Pandangan Dermatologis. USU ERepository.

Anugrah, R. (2016). Diagnostik dan Tatalaksana Onikomikosis. Cermin Dunia Kedokteran, 43(9), 675-678.

Ayanbimpe, G. M., Wapwera, S. D., \& Kuchin, D. (2010). Indoor Air Mycoflora of Residential Dwellings in Jos metropolis. African Health Sciences, 10(2).

Bitew, A. (2018). Dermatophytosis: Prevalence of Dermatophytes and NonDermatophyte Fungi from Patients Attending Arsho Advanced Medical Laboratory, Addis Ababa, Ethiopia. Dermatology Research and Practice, 2018.

Bongomin, F., Batac, C. R., Richardson, M. D., \& Denning, D. W. (2018). A Review of Onychomycosis Due to Aspergillus Species. Mycopathologia, 183(3), 485-493. https://doi.org/10.1007/s11046-0170222-9

Brown, G. D., Denning, D. W., Gow, N. A., Levitz, S. M., Netea, M. G., \& White, T. C. (2012). Hidden killers: human fungal infections. Sci Transl Med 4: $165 r v 13$.

Dubljanin, E., Džamić, A. M., Mitrović, S., Arsić-Arsenijević, V., \& ČolovićČalovski, I. (2014). Onychomycosis: Clinical Findings, Etiological Agents and Evaluation of Laboratory Methods. Archives of Biological Sciences, 66(2), 587-594. 
JURNAL ILMU KESEHATAN BHAKTI HUSADA:

HEALTH SCIENCES JOURNAL

VOL. 12 NO. 02, DESEMBER 2021

DOI: $10.34305 / \mathrm{JIKBH} . \mathrm{V} 12 \mathrm{I} 2.324$

Dwi Candra Arianti, I. S. (2015). Prevalensi, Agen Penyebab, dan Analisis Faktor Risiko Infeksi Tinea unguinum pada Peternak Babi di Kecamatan Tanah Siang, Provinsi Kalimantan Tengah. Jurnal Buski, 156.

Hasanah, U. (2017). Mengenal Aspergillosis, Infeksi Jamur Genus Aspergillus. Jurnal Keluarga Sehat Sejahtera, 15(2), 76-86.

Iqbal, N., Irfan, M., Zubairi, A. B. S., Jabeen, K., Awan, S., \& Khan, J. A. (2016). Clinical Manifestations and Outcomes of Pulmonary Aspergillosis: Experience from Pakistan. BMJ Open Respiratory Research, 3(1), e000155.

Irianto, K. (2013). Parasitologi Medis (Medical Parasitology). Bandung Alfabeta.

Iswanto, E. D. (2015). Analisis Pertumbuhan Tricophyton Mentagrophytes pada Media Tepung Beras (Oryza Sativa Linn) sebagai Media Alternatif Pengganti Potato Dextrose Agar. Politeknik Kesehatan Bandung.

Jellinek, N. J., Rich, P., \& Pariser, D. M. (2015). Understanding Onychomycosis Treatment: Mechanisms of Action and Formulation. Semin Cutan Med Surg, 34(3 Suppl), S51-3.

Kurniati, P. C. R. S. (2008). Etiopatogenesis dermatofitosis. Berkala Ilmu Kesehatan Kulit Dan Kelamin, 20(3), 243-250.

Lestari, W. (2017). Identifikasi Jamur Dermatofita pada Kuku Buruh Pembuat Genteng yang Mengalami
Ciptaan disebarluaskan di bawah

Lisensi Creative Commons Atribusi-

NonKomersial-BerbagiSerupa 4.0

Internasional.

Kerapuhan. Universitas Setia Budi Surakarta.

Martínez-Herrera, E. O., Arroyo-Camarena, S., Tejada-García, D. L., Porras-López, C. F., \& Arenas, R. (2015). Onychomycosis Due to Opportunistic Molds. Anais Brasileiros de Dermatologia, 90, 334-337.

Mizana, D. K., Suharti, N., \& Amir, A. (2016). Identifikasi Pertumbuhan Jamur Aspergillus Sp Pada Roti Tawar yang dijual di Kota Padang Berdasarkan Suhu dan Lama Penyimpanan. Jurnal Kesehatan Andalas, 5(2).

Puspita, L. T. (2013). Pusat Kegiatan bagi Penyayang serta Hewan Anjing dan Kucing di Daerah Istimewa Yogyakarta. Skripsi Fakultas Teknik Universitas Atma Jaya Yogyakarta.

Setianingsih, I., Arianti, D. C., \& Fadilly, A. (2016). Prevalensi, Agen Penyebab, dan Analisis Faktor Risiko Infeksi Tinea unguium pada Peternak Babi di Kecamatan Tanah Siang, Provinsi Kalimantan Tengah.

Universitas Brawijaya. (2012). Manual Prosedur Pelayanan Medis Klinik Hewan. Universitas Brawijaya. 